\title{
Prevalence of hepatitis B virus, hepatitis C virus, human immunodeficiency virus and Treponema pallidum infections in hospitalized patients before transfusion in Xiangya hospital Central South University, China from 2011 to 2016
}

Wei-Wei Cao ${ }^{1 \dagger}$, Rong-Rong Zhou ${ }^{2 \dagger}$, Xinghua Ou ${ }^{3}$, Ling-Xi Shi', Chao-Qi Xiao ${ }^{1}$, Ting-Yin Chen ${ }^{4}$, Hua Tan $^{5}$, Xue-Gong Fan' ${ }^{2}$ Bi-Juan $\mathrm{Li}^{1}$ and Ning $\mathrm{Li}^{i^{*}}$

\begin{abstract}
Background: Human immunodeficiency virus (HIV), hepatitis B virus (HBV), hepatitis C virus (HCV) and Treponema pallidum (TP) infections are considered classic transfusion-transmissible infections (TT/s). Few data are available about the prevalence of TTls in patients before blood transfusion in China. This study aimed to investigate the seroprevalence of four TTls among patients before blood transfusion in Xiangya Hospital Central South University, China.
\end{abstract}

Methods: From 2011 to 2016, 442,121 hospitalized patients before possible blood transfusion were tested for hepatitis B surface antigen (HBsAg), anti-HCV, syphilis antibody (anti-TP) and anti-HIV.

Results: Of the 442,121 patients, the overall positivity of the four $\Pi \mathrm{Tl}$ serum markers was $15.35 \%$. The positive rates of HBsAg, anti-HCV, anti-HIV and anti-TP were 10.98, 1.43, 0.16 and 2.78\%, respectively. Tा serum markers showed a significant difference by gender, with positive rates of $17.98 \%$ for males and $12.79 \%$ for females. The prevalence of TTI serum markers varied significantly by age. The overall co-infection rate was $0.63 \%$, and the top three multiple infections were HBV-TP, HBV-HCV, and HCV-TP. The co-infection rates of HBV-TP and HBV-HCV showed a significant decrease from 2011 to 2016, while the rates of other co-infections remained stable.

Conclusions: The prevalence of TTls in patients before blood transfusion is much higher compared to that in blood donors in the region. The infection rates of HIV and TP increased, and the infection rate of HBsAg decreased in recent years.

Keywords: Transfusion-transmissible infections, Human immunodeficiency virus, Viral hepatitis, Treponema pallidum, Blood transfusion

\footnotetext{
* Correspondence: nxli1970@126.com

tEqual contributors

${ }^{1}$ Department of Blood Transfusion of Xiangya Hospital, Central South

University, 87 Xiangya Road, Changsha 410008, Hunan Province, China

Full list of author information is available at the end of the article
} 


\section{Background}

Blood transfusion, especially component transfusion such as packed red blood cells, platelet concentrates, fresh frozen plasma, individual factor concentrates, and cryoprecipitate, has become an indispensable medical treatment for the rescue of patients. However, blood transfusion still has some limitations, and the most significant one is the potential risk of transfusiontransmitted infections (TTIs) [1, 2]. The pathogens involved in TTIs include viruses, bacteria and parasites [3]. Among them, hepatitis B virus (HBV), hepatitis $\mathrm{C}$ virus (HCV), human immunodeficiency virus (HIV) and Treponema pallidum (TP) are especially concerning because of their prolonged presence in the blood and body fluids of carriers [1-4].

With a general population infection rate of nearly 10 . $00 \%$ [5], the prevalence of chronic hepatitis $\mathrm{B}(\mathrm{CHB})$ is particularly serious in China. $\mathrm{CHB}$ and chronic $\mathrm{HCV}$ infection are strongly associated with liver failure, liver cirrhosis and cancer. In the early and mid-1990s in China, the anti-HCV antibody was not screened for in blood for transfusion, and this resulted in many cases of transfusion-transmitted hepatitis $C[6,7]$. Acquired immune deficiency syndrome (AIDS) caused by HIV infection has become one of the world's most serious health challenges. In 2005, 22,000 out of 75,000 newly developed HIV infections in China were acquired by transfusion of contaminated blood [8-10]. TP is an important bloodborne disease, and a resurgence of it has occurred in recent years in China [11]. Regardless of the manner of infection acquisition, timely detection and diagnosis of these TTIs is critical for the treatment of these patients and the prevention of the transmission.

The prevalence of TTIs varies greatly in different areas and populations. For instance, in western China, the prevalence rate of HIV infection in donors was $0.31 \%$ [12, 13]. While in Guangzhou and Nanjing, it was 0.02 and 0. 08\%, respectively [14]. Until now, most studies have focused on the positive rate of TTI serum markers among blood donors, while few studies have focused on the patients, especially these who will receive transfusion.

In the present study, we analyzed the results of tests on patients before possible blood transfusion at a comprehensive teaching hospital in the central and southern region of China and evaluated the positivity of $\mathrm{HBsAg}$, anti-HCV, anti-HIV and syphilis antibodies over a 6-year period. This study provides data about the prevalence and trends of these four TTIs in a large patient population.

\section{Methods}

The cross-sectional study was approved by "Medical Ethics Committee of the Xiangya Hospital of Centre South University" in the year 2010. Written informed consent was obtained from all the patients to allow the use of anonymized test results of their blood samples. Consent was obtained from a parent or guardian on behalf of any participants under the age of 16. Xiangya Hospital is a large-scale, comprehensive, tertiary hospital with 3500 beds and nearly 3 million outpatients and emergency patients each year. The patients at this hospital mainly come from the central and southern regions of China. From 2011 to 2016, TTI serum markers were tested in 442,121 patients who planned to receive blood transfusions, surgeries or interventional procedures at Xiangya Hospital.

\section{Serologic assays}

Serum samples were assessed for antibodies to HIV types 1 and 2 (anti-HIV1/2), HBsAg, anti-HCV and antiTP by chemiluminescence microparticle immunoassays (CMIA) on the ARCHITECT i2000SR (Abbott Diagnostics, Wiesbaden, Germany). All the reagents were provided by Abbott Company and were approved by the State Food and Drug Administration of China. The system provided standardized quantitative results for HBsAg, expressed in international units ( $\mathrm{IU} / \mathrm{ml}$ ), and values exceeding $0.05 \mathrm{IU} / \mathrm{ml}$ were considered positive for HBsAg. The presence or absence of anti-HIV $1 / 2$, anti-HCV or anti-TP in the sample was determined by comparing the chemiluminescent signal in the reaction to the cut-off signal determined from an active ARCHITECT anti-HIV1/2, anti-HCV or anti-TP calibration curve, respectively. All the results of anti-HIV1/2, anti$\mathrm{HCV}$ or anti-TP are expressed as the S/CO ratio, with $\mathrm{S} / \mathrm{CO}<1.0$ indicating a nonreactive result and $\mathrm{S} / \mathrm{CO} \geq 1$. 0 indicating a reactive result. The samples positive for anti-TP were confirmed with identical test kits. A result was considered positive only when both results were positive. Serum from patients who screened positive for anti-HIV1/2 was collected again on the second day and re-examined by CMIA and colloidal gold immunochromatographic assay (Wantai, Beijing, China). The HIV antigen was fixed on the membrane with the nitrocellulose membrane as the carrier, and the samples were migrated along the solid-phase carrier. The quality-control band of the effective test had to be developed. The positive results and the quality-control band each showed a colored stripe on the membrane antigen site. As long as one method of re-examination result was positive, the serum samples were retested to confirm the existence of HIV infection by Western blot, which was performed in the laboratory of Hunan Provincial Centers for Disease Control and Prevention (CDC) [15]. The operation methods and results of judgment strictly followed the national guideline for detection of HIV/AIDS formulated by the CDC. All reagents were of quality batches and were used within the validity period. 


\section{Statistical analysis}

Statistical analyses were conducted using SPSS 19.0 statistics software. The chi-square test was applied to assess associations between categorical variants. The chi-square test for trends was used to analyze the differences in the seroprevalence of HBsAg, anti-HCV, anti-HIV and antiTP among patients. A $p$-value $<0.05$ was considered statistically significant.

\section{Results}

\section{Demographic characteristics of patients}

A total of 442,121 patients were screened for serum markers of the four TTIs during the study period. Of them, 218,378 (49.39\%) were male, and 223,743 (50.61\%) were female. The age of the study subjects ranged from 0 to 99 years (the average age was 43.85), and patients aged from 21 to 50 years accounted for $52.91 \%$ of all the subjects. The details are shown in Table 1.

\section{Seroprevalence of HBV, HCV, HIV and TP}

The overall positivity of TTI serum markers was $15.35 \%$ (67875) and the positive rates of $\mathrm{HBsAg}$, anti-HCV, antiHIV and anti-TP were 10.98, 1.43, 0.16 and $2.78 \%$, respectively (Table 1). Among them, 14.06\% (62184) had one positive TTI serum marker, and $0.63 \%$ (2788) had two or more (Table 2).

Table 1 Socio-demographic characteristics of screened patients from Xiangya Hospital Central South University, China, 2011-2016

\begin{tabular}{lll}
\hline Characteristic & Number of patients screened & $\%$ \\
\hline Total & 442,121 & 100.00 \\
Gender & & \\
Male & 218,378 & 49.39 \\
Female & 223,743 & 50.61 \\
Age & & \\
<20 & 53,903 & 12.19 \\
$21-30$ & 71,362 & 16.14 \\
$31-40$ & 75,280 & 17.03 \\
$41-50$ & 87,275 & 19.74 \\
$51-60$ & 70,723 & 16.00 \\
$61-70$ & 55,256 & 12.50 \\
$\geq 71$ & 28,322 & 6.40 \\
Anti-HIV & & \\
Positive & 709 & 0.16 \\
HBsAg & & 10.98 \\
Positive & 48,536 & \\
Anti-HCV & & 1.43 \\
Positive & 6331 & \\
Anti-TP & & \\
Positive & 12,299 & \\
\hline
\end{tabular}

The positive rates of TTI serum markers were $17.98 \%$ for males and $12.79 \%$ for females $(p<0.001)$. HIV, HBV and HCV infection were more prevalent in males $(p<0$. 001). TP infection was more prevalent in females $(p=0$. 003) (Table 2).

The prevalence of TTI serum markers varied significantly by age group. The highest infection rate of HBV was found in the middle-young group (aged 3160 years), especially in those from 41 to 50 years old (14. $30 \%)$. The prevalence of HBsAg was lowest in those under the age of 20 years (2.34\%). Most infections of TP were identified in aged patients. The positive rates of anti-TP significantly increased with increasing age and reached a peak $(4.84 \%)$ in the age group older than 71 years. Likewise, the prevalence of $\mathrm{HCV}$ infection was high within those groups whose age exceeded 41 years. Overall, infection rates of HIV were relatively low, and those aged from 21 to 60 years had the highest positive rate of $0.19 \%$ (Table 2).

\section{Trends of Seroprevalence of HBV, HCV, HIV and TP}

The positive rate of $\mathrm{HBsAg}$ decreased from $12.61 \%$ in 2011 to $10.27 \%$ in $2016(p<0.001)$, while the positive rates of anti-HIV and anti-TP increased significantly (from $0.12 \%$ in 2011 to $0.19 \%$ in $2016(p=0.005)$ and from $2.32 \%$ in 2011 to $3.06 \%$ in $2016(p<0.001)$. The positive rate of anti-HCV remained relatively steady over the 6-year study period $(p=0.702)$.

The variation trends of the positive rates of anti-TP, anti-HCV and HBsAg in male and female patients year by year were consistent. The positive rates of anti-HIV in male patients increased year by year $(p=0.001)$, while in female patients, it remained relatively steady $(p=0.061)$ (Table 2).

Age- and year-related distribution figures showed that the positive rates of anti-HCV and anti-TP remained steady over the 6 years studied (Fig. 1c \& d). Decreased positivity of HBsAg was observed in all age groups when analyzed year by year (Fig. 1b). A significant increase in the positive rate of anti-HIV in 21-30-year-old patients was observed $(P=0.032)$ (Fig. 1a).

\section{Distribution of co-infections}

Of all the patients screened, $2788(0.63 \%)$ had multiple infections (Table 3). The top three multiple infections were $\mathrm{HBV}-\mathrm{TP}, \mathrm{HBV}-\mathrm{HCV}$, and $\mathrm{HCV}-\mathrm{TP}$, with positivity rates of $0.29,0.18$ and $0.06 \%$, respectively. Co-infection rates of HBV-TP and HBV-HCV showed significant decreases from 0.34 to $0.23 \%$ and 0.25 to $0.14 \%$, respectively $(p<0.001)$, while the seroprevalence of HIV-HBV showed a slight increase from 0.03 to $0.05 \%(p=0.020)$. The prevalence of triple or quadruple infection was rare and remained relatively steady. 
Table 2 Positive rates of HBsAg, anti-HCV, anti-HIV and anti-TP among patients from Xiangya Hospital Central South University, China, 2011-2016

\begin{tabular}{|c|c|c|c|c|c|c|}
\hline \multirow[t]{2}{*}{ Year } & \multirow{2}{*}{$\begin{array}{l}\text { Number of } \\
\text { patients } \\
\text { screened }\end{array}$} & \multirow{2}{*}{$\begin{array}{l}\text { Total } \\
\text { Number (\%) }\end{array}$} & \multirow{2}{*}{$\begin{array}{l}\text { Anti-HIV } \\
\text { Number (\%) }\end{array}$} & \multirow{2}{*}{$\begin{array}{l}\text { HBsAg } \\
\text { Number (\%) }\end{array}$} & \multirow{2}{*}{$\begin{array}{l}\text { Anti-HCV } \\
\text { Number (\%) }\end{array}$} & \multirow{2}{*}{$\begin{array}{l}\text { Anti-TP } \\
\text { Number (\%) }\end{array}$} \\
\hline & & & & & & \\
\hline \multicolumn{7}{|c|}{ Both male and female } \\
\hline 2011 & 53,779 & $8911(16.57)$ & $67(0.12)$ & $6779(12.61)$ & $820(1.53)$ & $1245(2.32)$ \\
\hline 2012 & 63,299 & $9729(15.37)$ & $106(0.17)$ & 7191 (11.36) & $806(1.27)$ & $1626(2.57)$ \\
\hline 2013 & 70,277 & $10,950(15.58)$ & $98(0.14)$ & 7963 (11.33) & $984(1.40)$ & $1905(2.71)$ \\
\hline 2014 & 78,709 & $12,177(15.47)$ & $123(0.15)$ & 8605 (10.93) & $1216(1.55)$ & $2233(2.84)$ \\
\hline 2015 & 83,888 & $12,263(14.62)$ & $144(0.17)$ & $8531(10.17)$ & $1123(1.34)$ & $2465(2.94)$ \\
\hline 2016 & 92,169 & $13,845(15.02)$ & $171(0.19)$ & $9467(10.27)$ & $1382(1.50)$ & $2825(3.06)$ \\
\hline$P$ & & 0.000 & 0.005 & 0.000 & 0.702 & 0.000 \\
\hline \multicolumn{7}{|l|}{ Male } \\
\hline 2011 & 26,697 & $5214(19.53)$ & $38(0.14)$ & $4182(15.66)$ & $438(1.64)$ & $556(2.08)$ \\
\hline 2012 & 31,555 & $5745(18.21)$ & $77(0.24)$ & $4436(14.06)$ & $423(1.34)$ & $809(2.56)$ \\
\hline 2013 & 34,852 & $6511(18.68)$ & $73(0.21)$ & $4976(14.28)$ & $517(1.48)$ & $945(2.71)$ \\
\hline 2014 & 38,205 & $6964(18.23)$ & $83(0.22)$ & $5194(13.60)$ & $622(1.63)$ & $1065(2.79)$ \\
\hline 2015 & 40,443 & 7003 (17.32) & $99(0.25)$ & $5150(12.73)$ & $585(1.45)$ & $1169(2.89)$ \\
\hline 2016 & 46,626 & $7817(16.77)$ & $125(0.27)$ & $5631(12.08)$ & $694(1.49)$ & $1367(2.93)$ \\
\hline$P$ & & 0.000 & 0.001 & 0.000 & 0.108 & 0.000 \\
\hline Total & 218,378 & $39,254(17.98)$ & $495(0.23)$ & 29,569 (13.54) & 3279 (1.50) & $5911(2.71)$ \\
\hline \multicolumn{7}{|l|}{ Female } \\
\hline 2011 & 27,082 & 3697 (13.65) & $29(0.11)$ & 2597 (9.59) & $382(1.41)$ & $689(2.54)$ \\
\hline 2012 & 31,744 & 3984 (12.55) & $29(0.09)$ & 2755 (8.68) & $383(1.21)$ & $817(2.57)$ \\
\hline 2013 & 35,425 & 4439 (12.53) & $25(0.09)$ & 2987 (8.43) & $467(1.32)$ & $960(2.71)$ \\
\hline 2014 & 40,504 & $5213(12.87)$ & $40(0.10)$ & 3411 (8.42) & $594(1.47)$ & $1168(2.88)$ \\
\hline 2015 & 43,445 & $5260(12.11)$ & $45(0.10)$ & 3381 (7.78) & $538(1.24)$ & $1296(2.98)$ \\
\hline 2016 & 45,543 & $6028(13.24)$ & $46(0.10)$ & $3836(8.42)$ & $688(1.51)$ & $1458(3.20)$ \\
\hline$P$ & & 0.112 & 0.805 & 0.000 & 0.279 & 0.000 \\
\hline Total & 223,743 & $28,621(12.79)$ & $214(0.10)$ & $18,967(8.48)$ & 3052 (1.36) & $6388(2.86)$ \\
\hline \multicolumn{7}{|l|}{ Age } \\
\hline$\leq 20$ & 53,903 & 2112 (3.92) & $45(0.09)$ & 1259 (2.34) & $351(0.65)$ & $457(0.85)$ \\
\hline $21-30$ & 71,362 & $9730(13.63)$ & $131(0.18)$ & 7695 (10.78) & $689(0.97)$ & $1215(1.70)$ \\
\hline $31-40$ & 75,280 & $13,983(18.57)$ & $146(0.19)$ & $10,697(14.21)$ & $1028(1.37)$ & $2112(2.81)$ \\
\hline $41-50$ & 87,275 & 16,911 (19.38) & $166(0.19)$ & $12,483(14.30)$ & 1536 (1.76) & $2726(3.12)$ \\
\hline $51-60$ & 70,723 & $12,288(17.37)$ & $130(0.18)$ & 8653 (12.24) & $1253(1.77)$ & 2252 (3.18) \\
\hline $61-70$ & 55,256 & $8968(16.23)$ & $76(0.14)$ & 5751 (10.41) & $975(1.76)$ & 2166 (3.92) \\
\hline$\geq 71$ & 28,322 & $3883(13.71)$ & $15(0.05)$ & 1998 (7.05) & $499(1.76)$ & $1371(4.84)$ \\
\hline$P$ & & 0.000 & 0.000 & 0.000 & 0.000 & 0.000 \\
\hline
\end{tabular}

\section{Discussion}

The detection of TTI markers before blood transfusion in recipients is not only an important measure to reduce or eliminate medical disputes caused by infections through blood transfusion but also an effective way to reduce the iatrogenic infection and occupational exposure risk of doctors and nurses. Currently, available data about the prevalence of TTIs in recipients is limited, and our study supplies a relatively large amount of patient population data. Part of our data had been presented before at the 26th Annual Conference of APASL in Shanghai [16]. Of the 442,121 patients involved, 15. $35 \%$ had a minimum of one positive TTI serum marker, and $0.63 \%$ had two or more. The prevalence of most 

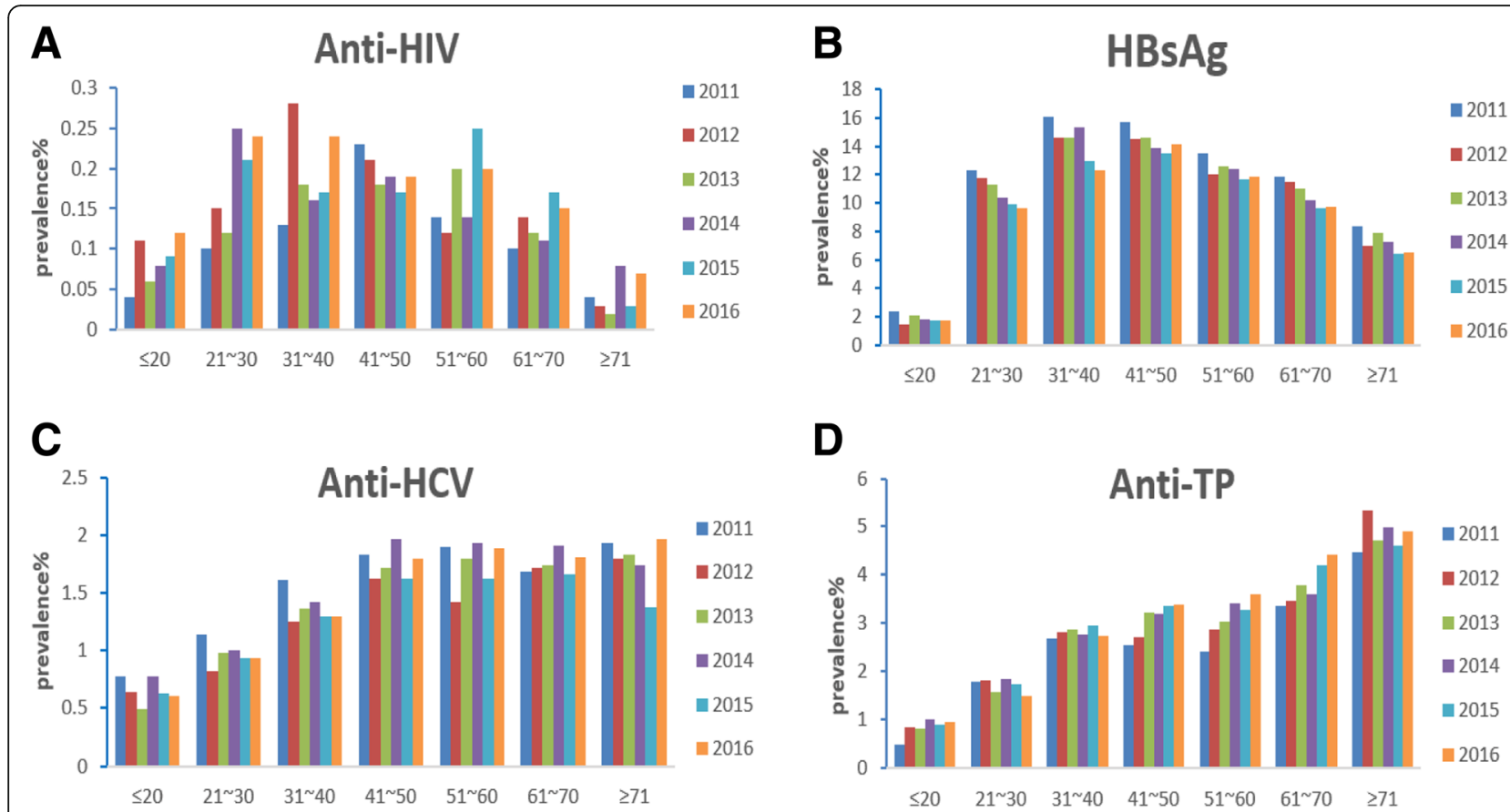

Fig. 1 Trends of age- related positive rates of HBsAg (panel b), aAnti-HCV (panel c), Aanti-HIV (panel a), and Aanti-TP (panel d), in patients from Xiangya Hospital Central South University, China, 2011-2016

TTIs in patients is higher than that in the general population and healthy donors. The positive rates of TTI serum markers in males are significantly higher than that in females.

The HBV serum epidemiology survey in China in the year 2006 indicated that the rate of HBsAg positivity was $7.18 \%$ in people aged $1-59$ years [5], which showed that China has changed from a high- into an intermediateprevalence area. In our study, the patients' positivity of HBsAg was $10.98 \%$, which is much higher than the 7 .
$80 \%$ in the general population and the $0.51-1.16 \%$ in blood donors [12, 13, 17]. Seropositive rate of HBsAg was significantly higher in men than women that is consistent with previous reports. In data from a national survey in China in 2014, HBsAg positivity in people aged 1-4 years, 5-14 years and 15-29 years was 0.32, 0.94 and $4.38 \%$, respectively. This decrease in young people was closely related to the national vaccination program implemented in 1992, which ensured that free HBV vaccination was provided for all neonates born in China

Table 3 Prevalence of co-infections among patients from Xiangya Hospital Central South University, China, 2011-2016

\begin{tabular}{|c|c|c|c|c|c|c|c|}
\hline \multirow[t]{2}{*}{ Co-infections } & 2011 & 2012 & 2013 & 2014 & 2015 & 2016 & Total \\
\hline & Number(\%) & Number(\%) & Number(\%) & Number(\%) & Number(\%) & Number(\%) & Number(\%) \\
\hline HBV-TP ${ }^{a}$ & $181(0.34)$ & $222(0.35)$ & $230(0.33)$ & $243(0.31)$ & $202(0.24)$ & $214(0.23)$ & $1292(0.29)$ \\
\hline $\mathrm{HBV}-\mathrm{HCV}^{\mathrm{a}}$ & $132(0.25)$ & $135(0.21)$ & $148(0.21)$ & $138(0.18)$ & $123(0.15)$ & $129(0.14)$ & $805(0.18)$ \\
\hline HCV-TP & $43(0.08)$ & $39(0.06)$ & $43(0.06)$ & $38(0.05)$ & $47(0.06)$ & $57(0.06)$ & $267(0.06)$ \\
\hline HIV-HBV a & $14(0.03)$ & $16(0.03)$ & $27(0.04)$ & $34(0.04)$ & $28(0.03)$ & $48(0.05)$ & $167(0.03)$ \\
\hline HIV-TP & $10(0.02)$ & $19(0.03)$ & $15(0.02)$ & $21(0.03)$ & $27(0.03)$ & $32(0.03)$ & $124(0.03)$ \\
\hline HIV-HCV & $4(0.01)$ & $8(0.01)$ & $3(0.00)$ & $4(0.01)$ & $8(0.01)$ & $12(0.01)$ & $39(0.01)$ \\
\hline HBV-HCV-TP & $14(0.03)$ & $5(0.01)$ & $16(0.02)$ & $6(0.01)$ & $5(0.01)$ & $5(0.01)$ & $51(0.01)$ \\
\hline HIV-HBV-TP & $1(0.00)$ & $5(0.01)$ & $5(0.01)$ & $5(0.01)$ & $4(0.01)$ & $5(0.01)$ & $25(0.01)$ \\
\hline HIV-HBV-HCV & 0 & 0 & $3(0.00)$ & $3(0.00)$ & $1(0.00)$ & $4(0.00)$ & $11(0.00)$ \\
\hline HIV-HCV-TP & $1(0.00)$ & 0 & $2(0.00)$ & $1(0.01)$ & $1(0.00)$ & $2(0.00)$ & $7(0.00)$ \\
\hline HIV-HBV-HCV-TP & 0 & 0 & 0 & 0 & 0 & 0 & 0 \\
\hline Total ${ }^{a}$ & $400(0.74)$ & $449(0.71)$ & $492(0.70)$ & $493(0.63)$ & $446(0.53)$ & $508(0.55)$ & $2788(0.63)$ \\
\hline
\end{tabular}

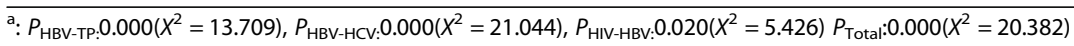


[18]. In this research focused on patients, HBsAg prevalence peaked in the 41-50-year age group, and a declining trend was observed in young patients, which is in accordance with the general population. Nevertheless, $\mathrm{CHB}$ is still one of the most important infectious diseases in China, especially in the patient population.

Our research showed the positive rate of anti-HCV was $1.43 \%$, which was much higher than the $0.43 \%$ reported in the general population in 2006 in China [19]. The positivity of anti-HCV in our patient group was significantly lower than $2.8 \%$, the average level in the world, and this further supports the assertion that China is a low-epidemic area of $\mathrm{HCV}[6,7]$. The prevalence of HCV infection was high within those aged 41-70 years (1.76\%). In China, blood transfusion was an important transmission route of $\mathrm{HCV}$ and HIV before the Blood Donation Law came into effect in 1998 [20-22]. This may partly explain the reason that $\mathrm{HCV}$ infection was especially high in those aged people.

China has experienced a dramatic resurgence of syphilis in recent years [11]. The total positive rate of anti-TP was $2.78 \%$, and most infections of TP were identified in aged patients. This result was consistent with that of previous studies [23]. Approximately $18 \%$ of anti-TP positive patients aged $\geq 70$ years had false results due to the limitations in the detection methods caused by interference by other diseases [24]. To correct this bias, some of the CMIA anti-TP-positive results were confirmed by TPPA assay in our study, but the false-positive rate of the CMIA assay was only $0.16 \%$ (Additional file 1 ). Therefore, the positive rate of $4.98 \%$ might be slightly higher than the real level, but the elderly infected patients, who are commonly not well educated and face the problem of economic and moral condemnation, should not be ignored [25-27]. Unlike CHB and AIDS, infection with HCV and TP is treatable. If treatment is not applied duly, some irreversible complications may lead to poor clinical outcomes. Thus, early detection and therapy in these asymptomatic patients is necessary.

The overall infection rate of HIV was $0.16 \%$ and showed an increasing trend in recent years. The most significant increases were observed in patients aged 2130 years. In China, HIV transmission was particularly high among injection drug users (IDUs) and former plasma donors from 1985 to 2006 [9, 20, 28]. However, in recent years, sexual transmission (both heterosexual and homosexual) has become the dominant route [28]. Our study showed that the peak of HIV infections occurred in a sexually active age. In our study the infection rate of HIV in men $(0.23 \%)$ was significantly higher than that in women $(0.10 \%)$. Available data indicated that the HIV epidemic among men who have sex with men (MSM) has been rapidly expanding in recent years in China $[29,30]$. The prevalence of TTI co-infection was
$0.63 \%$ in our patient population, and its reported positivity in donors varies among areas ranged from 0.80 to 6 . $29 \%[2,13,31]$. This is probably due to the fact that the pathogens in co-infection conditions share similar routes of transmission, including sharing needles and high-risk sexual behaviors.

The Blood Donation Law in China prohibited the use of paid blood donation and required testing for the four TTIs discussed in this study in donors and in blood products for input. As a result, volunteer donors without payment now constitute the majority of blood donors. This transformation in the composition of blood donors has been associated with a gradual decrease in the prevalence of transfusion-transmitted HCV and HIV [9, 22]. In addition, the use of clean and disposable injection equipment has helped to prevent the transmission of blood borne diseases. At present, the most concerning problem is the transmission of these diseases through sexual contact and IDUs [29].

\section{Conclusions}

The prevalence of HBV, HCV, HIV and TP infections in patients before blood transfusion in central and south China is relatively high. The overall infection rate of HBV is high but declining in young patients, while the infection rate of HIV is relatively low but showing an upward trend. Identification of these TTI serum markers in patients before blood transfusion is strongly recommended because it could facilitate the discovery of potential infectious diseases, reduce the chance of nosocomial infection of these diseases during medical treatment and provide useful epidemiological information about TTIs in certain areas.

\section{Additional file}

Additional file 1: Preliminary screening and validation of TP antibodies in 2016. Table S1. The distribution of TPPA positive specimens in different S/CO values in 2825 cases. (DOCX $30 \mathrm{~kb}$ )

\section{Abbreviations \\ AIDS: Acquired immune deficiency syndrome; CDC: Centers for Disease Control and Prevention; CHB: Chronic hepatitis B; CMIA: Chemiluminescence microparticle immunoassays; HBsAg: Hepatitis B surface antigen; HBV: Hepatitis B virus; HCV: Hepatitis C virus; HIV: Human immunodeficiency virus; IDU: Injection drug user; MSM: Men who have sex with men; TP: Treponema pallidum; TTls: Transfusion-transmissible infections}

\section{Acknowledgments}

We would like to thank all the patients for their participation. We are sincerely grateful to the clinicians and nurses for their help.

\section{Funding}

This work was supported by a grant from the research project of the Health and Family Planning Commission of Hunan province (No. A2016015). The sponsor had no role in the design of the study, the collection, analysis, and interpretation of data or in writing the manuscript. 


\section{Availability of data and materials}

The dataset of the current study is available from the corresponding author upon reasonable request.

\section{Authors' contributions}

CWW and ZRR participated in the sampling, data analysis and drafting of the manuscript; OXH, CTY and TH participated in the sampling; SLX and XCQ participated in the serologic assays; FXG and LBJ participated in the design and coordination of the project; and LN participated in the conception and design of the study and review of the final manuscript. All authors read and approved the final manuscript.

\section{Ethics approval and consent to participate}

The study protocol was approved by the "Medical Ethics Committee of the Xiangya Hospital of Centre South University". Before enrollment, all participants received a brief explanation of the aims, risks and benefits of the study. The participants signed an informed consent form. Consent was obtained from a parent or guardian on behalf of any participants under the age of 16 .

\section{Consent for publication}

Not applicable.

\section{Competing interests}

The authors declare that they have no competing interests.

\section{Publisher's Note}

Springer Nature remains neutral with regard to jurisdictional claims in published maps and institutional affiliations.

\section{Author details \\ ${ }^{1}$ Department of Blood Transfusion of Xiangya Hospital, Central South University, 87 Xiangya Road, Changsha 410008, Hunan Province, China. ${ }^{2}$ Department of Infectious Diseases, Xiangya Hospital, Central South University, Changsha, China. ${ }^{3}$ Center for Disease Prevention and Control of Changsha, Changsha, China. ${ }^{4}$ Department of Information of Xiangya Hospital, Central South University, Changsha, China. ${ }^{5}$ Center for Disease Prevention and Control of Kaifu District, Changsha, China.}

Received: 12 November 2017 Accepted: 20 March 2018 Published online: 02 April 2018

\section{References}

1. Seitz R, Heiden M. Quality and safety in blood supply in 2010. Transfus Med Hemother. 2010;37:112-7.

2. Xie DD, Li J, Chen JT, Eyi UM, Matesa RA, Obono MM, et al. Seroprevalence of human immunodeficiency virus, hepatitis B virus, hepatitis $C$ virus, and Treponema pallidum infections among blood donors on Bioko Island, Equatorial Guinea. PLoS One. 2015;10:e0139947.

3. Bloch EM, Vermeulen M, Murphy E. Blood transfusion safety in Africa: a literature review of infectious disease and organizational challenges. Transfus Med Rev. 2012;26:164-80.

4. Flichman DM, Blejer JL, Livellara Bl, Re VE, Bartoli S, Bustos JA, et al. Prevalence and trends of markers of hepatitis B virus, hepatitis $C$ virus and human immunodeficiency virus in argentine blood donors. BMC Infect Dis. 2014;14:218.

5. Hou JL, Lai W. The guideline of prevention and treatment for chronic hepatitis B: a 2015 update. Zhonghua Gan Zang Bing Zhi. 2015;23:888-905.

6. Gower E, Estes C, Blach S, Razavi-Shearer K, Razavi H. Global epidemiology and genotype distribution of the hepatitis $C$ virus infection. J Hepatol. 2014;61:S45-57.

7. Mohd Hanafiah K, Groeger J, Flaxman AD, Wiersma ST. Global epidemiology of hepatitis C virus infection: new estimates of age-specific antibody to HCV seroprevalence. Hepatology. 2013;57:1333-42.

8. Sheng L, Cao WK. HIV/AIDS epidemiology and prevention in China. Chin Med J. 2008;121:1230-6.

9. Shan H, Wang JX, Ren FR, Zhang YZ, Zhao HY, Gao GJ, et al. Blood banking in China. Lancet. 2002;360:1770-5.

10. China Ministry of Health, Joint United Nations Programme on HIV/IADS, World Health Organization. 2005 update on the HIV/AIDS epidemic and response in China. Beijing: National Center for AIDS/STD Prevention and Control, China CDC; 2006.
11. Liu J, Huang Y, Wang J, Guo N, Li J, Dong X, et al. The increasing prevalence of serologic markers for syphilis among Chinese blood donors in 2008 through 2010 during a syphilis epidemic. Transfusion. 2012;52:1741-9.

12. Ji ZH, Li CY, LV YG, Cao W, Chen YZ, Chen XP, et al. The prevalence and trends of transfusion-transmissible infectious pathogens among first-time, voluntary blood donors in Xi'an, China between 1999 and 2009. Int J Infect Dis. 2013;17:e259-62.

13. Song $Y$, Bian $Y$, Petzold $M$, Ung CO. Prevalence and trend of major transfusion-transmissible infections among blood donors in western China, 2005 through 2010. PLoS One. 2014;9:e94528.

14. Li C, Xiao X, Yin H, He M, Li J, Dai Y, et al. Prevalence and prevalence trends of transfusion transmissible infections among blood donors at four Chinese regional blood centers between 2000 and 2010. J Transl Med. 2012;10:176.

15. Chen X, He JM, Ding LS, Zhang GQ, Zou XB, Zheng J. Prevalence of hepatitis B virus and hepatitis $C$ virus in patients with human immunodeficiency virus infection in Central China. Arch Virol. 2013;158:1889-94.

16. Abstracts of the 26th Annual Conference of APASL, February 15-19, 2017, Shanghai, China. Hepatol Int. 2017 Feb;11(Suppl 1):1-1093. doi: https://doi. org/10.1007/s12072-016-9783-9.

17. Zheng X, Ding W, Li G, Wu Y, Wu D, Zhu H, et al. Seroprevalence of transfusion-transmissible infectious agents among volunteer blood donors between 2006 and 2012 in Zhejiang, China. Blood Transfus. 2015:13:401-10.

18. Liao XY, Zhou ZZ, Wei FB, Qin HN, Ling Y, Li RC, et al. Seroprevalence of hepatitis $B$ and immune response to hepatitis $B$ vaccination in Chinese college students mainly from the rural areas of western China and born before HBV vaccination integrated into expanded program of immunization. Hum Vaccin Immunother. 2014;10:224-31.

19. Chen YS, Li L, Cui FQ, Xing WG, Wang L, Jia ZY, et al. A seroepidemiological study on hepatitis C in China. Zhonghua Liu Xing Bing Xue Za Zhi. 2011;32:888-91.

20. Su B, Liu L, Wang F, Gui X, Zhao M, Tien P, et al. HIV-1 subtype B' dictates the AIDS epidemic among paid blood donors in the Henan and Hubei provinces of China. AIDS. 2003;17:2515-20.

21. Shepard CW, Finelli L, Alter MJ. Global epidemiology of hepatitis C virus infection. Lancet Infect Dis. 2005;5:558-67.

22. Zhao SM, Jiang TL, Li RQ, Gao FX, Lu L, Zheng HQ, et al. HCV infection in voluntary donors and its influence on recruitment of donors in Chongqing area. Zhongguo Shi Yan Xue Ye Xue Zhi. 2008;16:676-80.

23. Xu K, Chi S, Chen B, Chen L, Zheng D. The distribution of syphilis among inpatients in Wenzhou, China: a hospital based study. Jundishapur J Microbiol. 2016;9:e27825.

24. Bosshard PP, Graf N, Knaute DF, Kündig T, Lautenschlager S, Weber R. Response of Treponema pallidum particle agglutination test titers to treatment of syphilis. Clin Infect Dis. 2013;56:463-4.

25. Ganesan A, Fieberg A, Agan BK, Lalani T, Landrum ML, Wortmann G, et al. Results of a 25-year longitudinal analysis of the serologic incidence of syphilis in a cohort of HIV-infected patients with unrestricted access to care. Sex Transm Dis. 2012:39:440-8.

26. Chen ZQ, Zhang GC, Gong XD, Lin C, Gao X, Liang GJ, et al. Syphilis in China: results of a national surveillance programme. Lancet. 2007:369:132-8.

27. Tucker JD, Chen XS, Peeling RW. Syphilis and social upheaval in China. N Engl J Med. 2010;362:1658-61.

28. Marienfeld C. Heroin addiction, methadone, and HIV in China. Lancet Psychiatry. 2016;3:799-800

29. Pan SW, Li D, Carpiano RM, Spittal PM, Ruan Y. Ethnicity and HIV epidemiology research in China. Lancet. 2016;388:1052-3.

30. Oin Q, Tang W, Ge L, Li D, Mahapatra T, Wang L, et al. Changing trend of $H I V$, syphilis and hepatitis $C$ among men who have sex with men in China. Sci Rep. 2016;6:31081.

31. Dong R, Qiao X, Jia W, Wong M, Qian H, Zheng X, et al. HIV, HCV, and HBV co-infections in a rural area of Shanxi Province with a history of commercial blood donation. Biomed Environ Sci. 2011;24:207-13. 